\title{
Forming Behavior of ABS and PC Polymers under Plastic Injection Molding Process
}

\author{
O.S. KAMBER* \\ Ihlas Ev Aletleri A.Ş., 34524 Beylikdüzü, Istanbul, Turkey
}

\begin{abstract}
Remote control devices are tools that are used by people in their daily life. Dimensional instabilities on remote control results in many disadvantages in production, assembly phases, and ergonomic problem in use. Therefore in this study, the effects of various parameters including cold and hot runner system, process temperature on important dimensional measurements such as shrinkage and warpage is investigated. To manufacture remote control covers, two different plastic materials, acrylonitrile butadiene styrene (ABS) and polycarbonate (PC), are used. Thus the forming response of these materials is also investigated and compared in this study. Plastic injection process of these two materials to produce remote control is simulated by utilizing commercially available computer aided engineering software. The experimental findings were compared with the numerical results to compare shrinkage percentage and warpage ratio. Remote control cover part was produced by using cold runner system and hot runner system at constant injection pressure and different process temperatures. The results showed that as process temperature increases, volumetric shrinkage and warpage continuously increase for both ABS and PC raw material. Besides, cold runner system almost always generates much larger percentages of shrinkage and much larger warpage as compared with hot runner system.
\end{abstract}

DOI: 10.12693/APhysPolA.134.365

PACS/topics: plastic injection molding, plastic materials, warpage, numerical solution

\section{Introduction}

As a production method plastic injection molding is the most common method in producing plastic parts. Most vital parameters in plastic injection molding are part design, achieving a prototype with rapid prototyping, mould design, analyzing via computer aided engineering, verification, and lastly the injection process respectively. All these parameters are the factors affecting the plastic part quality to be manufactured. Among these parameters, choosing of the runner system that belongs to the mould design section is one of the most crucial factors which affect the part dimension stability. Initial investment costs of classic cold runner system are negligible but they bear lots of disadvantages.

Contrary to this, aside from the first investment costs of hot runner systems being rather high, the biggest advantage it provides is the ensuring of the uniform flow and realizing of equal heat distribution in the molding. Accordingly, aesthetic and dimensional stability of the part becomes stable. Besides thanks to the hot runner systems, traces of runner inlets on the plastic part are eliminated and the part becomes brighter esthetically which is desired properties for meeting customer's expectations. Computer aided engineering (CAE) programs help designers to find out the proper injection technologies. Thanks to these programs, manufacturability and production performance can be increased substantially. Beforehand, researchers conducted a number of studies

*e-mail: okamber@iea.com.tr regarding shrinkage and warpage. Spina [1] did the runner design of a medium-sized plastic part with Moldflow program. He reported the observations he had done according to these studies and conducted the evaluations of the aesthetic and volumetric warpage shrinkage ratio. Conducted studies showed that CAE programs provide help to engineers in determining the amount of deviation on warpaged surfaces, evaluating runner positions and preparing the mould design [1]. Bushko and Stokes [2] examined shrinkage and warpage on five different materials and proved that the most vital factors affecting the measure completeness are the packing pressure and melt temperature. Jansen et al. [3] conducted studies on packing pressure and melt temperature. They noted by testing on seven different thermoplastics that with the increase in the packing pressure, shrinkage diminishes, yet with the increase in the melt temperature, shrinkage increases. Soydan and Kapti [4] determined the effects to occur on the part quality in the case of implementing hot and cold runner systems into plastic injection moldings. In this study, the effects of runner systems on density, shrinkage, warpage, and the injection pressure were examined and vital findings were obtained. The shrinkage and warpage ratio in the moldings manufactured with hot runner systems was determined to be lower than the cold runner moldings. Huang et al. [5] examined the factors that affect warpage on a thin-section plastic part. CAE analyses were conducted by the CMold program. Obtained results were evaluated with the Taguchi method. According to the conducted study, factors affecting the warpage on an order of importance are packing pressure, molding temperature, melt temperature, packing time, runner position and filling phase. 
Hassan et al. [6] examined the effect of the runner inlet point on shrinkage, warpage and residual stress in the chilling of the polymer material. Kovacs and Siklo [7] developed a new measuring method by making a plastic sample part molding in $\mathrm{V}$ type different from the currently undergoing studies. Parameters which are approached in this paper are molding temperature, molding temperature difference, packing pressure, and glass fiber reinforcement. These parameters were examined by trying three different runner inlets and as a result it was determined that when glass fiber material is used for production, it has almost no effect on the warpage of the packing pressure. Erzurumlu and Özçelik [8] used the Taguchi method. They conducted investigations of warpage and sink in plastic parts on different rib sectional and rib plane angles. Transaction parameters that were used here were examined by implementing molding temperature, packing pressure, rib sectional types and rib plane angles. Polymeric tools used in the experiments are PC/ABS, POM and PA 66. Using orthogonal Taguchi analysis, variance analysis (ANOVA), optimum values of the process parameters were investigated for warpage and sink. Liao et al. [9] investigated the effects of process parameters between each other for thin cell phone open cover. L 27 experimental Taguchi methods were used. Poly Cad and Poly Works programs were used to define shrinkage and warpage. Optimum process conditions are different for shrinkage and warpage. In this study, optimum process conditions were found experimentally to decrease shrinkage and warpage with the Taguchi method. Molding temperature, melt temperature, packing pressure and injection speed; these were taken as the Taguchi factors.

Pomerleau and Sanschagrin [10], by putting orthogonal marks on the molding in a plane, compared the regional shrinkage values with measures in the plane on part's surface. It was used in finding the measures that are parallel and perpendicular to the profilograph flow. A sensitiveness analysis was used in finding the values that cause shrinkage. The effect of the packing pressure and injection speed on shrinkage was investigated experimentally. Liad and Hsieh [11] reported the estimation of shrinkage and warpage in the parts those of thin wall thickness by using artificial neural networks. Kurt et al. [12] investigated influence of molding conditions on the shrinkage and roundness of injection molded parts. In this study, the effects of molding parameters including packing pressure, melt temperature, and cooling time on shrinkage and roundness have been investigated experimentally. Also, the relationship among initial molding parameters, the cavity pressure, and mold temperature was investigated. This study illustrated that packing pressure and melt temperature are dominant factors which determine the quality of parts. Liu et al. [13] investigated the effects of process parameters such as melt temperature, mold temperature, and melt filling rate on the surface gloss of plastic parts produced with water assisted injection molding. Pigmented polypropylene was used as the polymer in this study. It was observed that increase of melt temperature decreases the surface gloss of material. Also, crystallinity and molecular chain orientation induced by shear stress in the molded parts may affect the surface gloss. Oliveira et al. [14] investigated the effect of injection parameters on the surface gloss of the ABS plastic parts. It was observed that if the mould cavity surface is very smooth, the surface gloss of the molded parts increase with the mold temperature, melt temperature, and the holding pressure increase. The increase of these parameters causes opposite effect with the other surfaces.

As comprehensive literature review presented above shows that no study shows the effects of hot and cold runner system on dimensional accuracy including warpage and shrinkage of molded parts made of ABS and PC. Because of these important points, this study provides experimental data that can be very useful for industry and academic studies. Bedsides, numerical simulation of molding process of these two materials is presented to compare with experimental data.

\section{Experimental procedure}

The remote control cover is a complex part in which wall thickness is not uniform and which contains holes, ribs, hard-edge forms with radius. Main measures of the part are $125.23 \mathrm{~mm} \times 28.78 \mathrm{~mm} \times 13.7 \mathrm{~mm}$ and the average wall thickness is $2.4 \mathrm{~mm}$. At some places, wall thickness even reaches $5.6 \mathrm{~mm}$. The $2 \mathrm{D}$ and $3 \mathrm{D}$ drawing of the part is shown in Fig. 1.
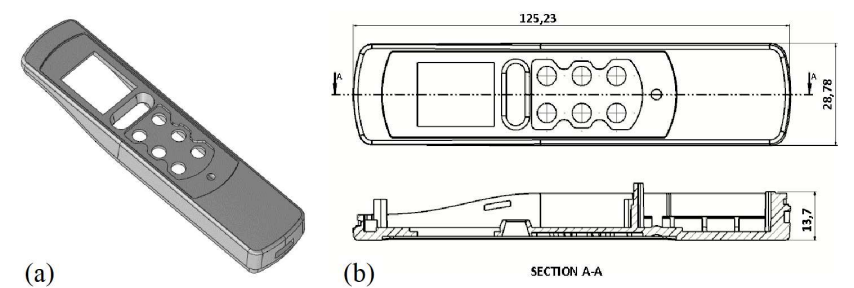

Fig. 1. (a) 3D and (b) 2D drawing of the part.

Mould was designed with SolidWorks Premium Program and produced such that both cold runner and hot runner is arranged in the same runner point in the same mould. To ensure measure stability and to minimize warpage, male and female parts and cores of mold were exposed to the cooling process in the same temperatures. Figure 2 shows the 3D drawing of the designed mold and its photographs.

In this study ABS and PC polymers are used as raw materials. ABS HI-121 is an amorphous polymer produced by LG Chem and PC1803R is an amorphous polymer produced by Sabic Innovative Plastics. The process temperature range is $210-240^{\circ} \mathrm{C}$ for $\mathrm{ABS}$ and $170-260^{\circ} \mathrm{C}$ for PC. The detailed specification of these polymers is shown in Table I. 

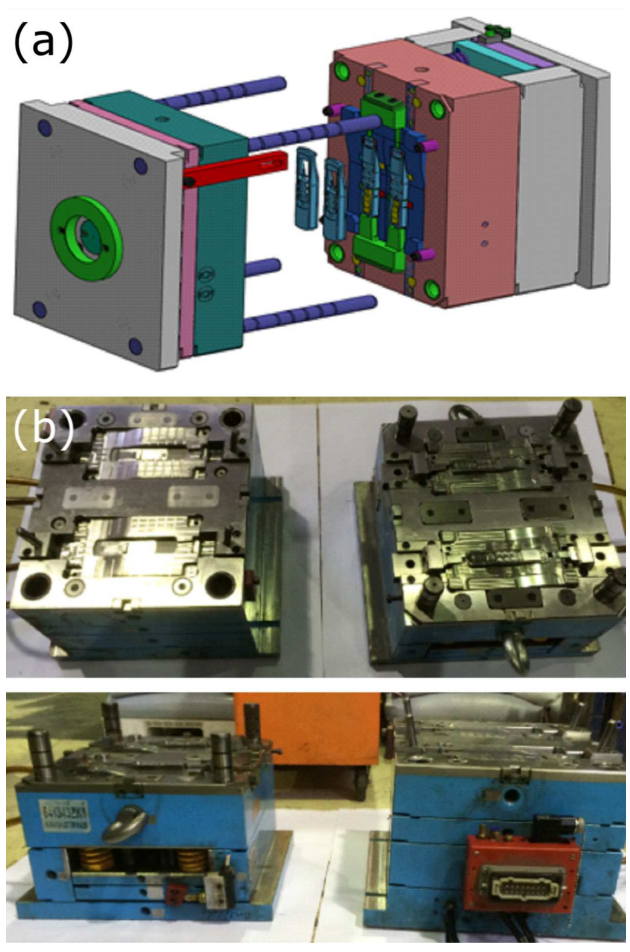

Fig. 2. (a) 3D drawing of designed mold, (b) photograph of produced molds.

Specifications of the molding materials

TABLE I

\begin{tabular}{l|c|c}
\hline \hline \multicolumn{1}{c|}{ Material } & ABS & PC \\
\hline commercial name & ABS HI-121 & PC1803R \\
\hline resin type & \multicolumn{2}{|c}{ amorphous } \\
\hline density & $1.04 \mathrm{~g} / \mathrm{cm}^{3}$ & $1.20 \mathrm{~g} / \mathrm{cm}^{3}$ \\
\hline melt flow index & $7 \mathrm{~g} / 10 \mathrm{~min}$ & $18 \mathrm{~g} / 10 \mathrm{~min}$ \\
& $\left(230^{\circ} \mathrm{C} / 3.8 \mathrm{~kg}\right)$ & $\left(300^{\circ} \mathrm{C} / 1.2 \mathrm{~kg}\right)$ \\
\hline process temperature & $200-240^{\circ} \mathrm{C}$ & $280-300^{\circ} \mathrm{C}$ \\
\hline tensile strength & $45.1 \mathrm{MPa}$ & $63 \mathrm{MPa}$ \\
\hline flexural modulus & $2450 \mathrm{MPa}$ & $2300 \mathrm{MPa}$
\end{tabular}

The brand name and model of the injection molding machine are Haitian and HTFX150. It has 150 tonnes clamping force and $230 \mathrm{~g}$ shot capacity. The remote control devices cover parts are produced at constant injection pressure in different melt temperatures with ABS and PC polymers and both hot runner system and cold runner system.

ABS parts were produced with 5 different temperature in the $200-240^{\circ} \mathrm{C}$ temperature range that manufacturer defined. PC parts were produced with 5 different temperature in the $280-300^{\circ} \mathrm{C}$ temperature range that manufacturer defined. The injection pressure was $80 \mathrm{MPa}$, packing pressure was $40 \mathrm{MPa}$, mold temperature for $\mathrm{ABS}$ row material was $40^{\circ} \mathrm{C}$, for PC material it was $80^{\circ} \mathrm{C}$, cycle time for ABS material was $40 \mathrm{~s}$, it was $50 \mathrm{~s}$ for PC material. Injection velocity was $0.012 \mathrm{~m} / \mathrm{s}$ for ABS material and it was $0.02 \mathrm{~m} / \mathrm{s}$ for PC material. The photographs of the produced parts are shown in Fig. 3.
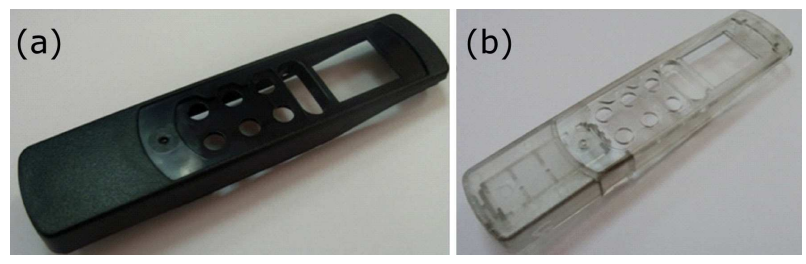

Fig. 3. The photographs of produced parts made of (a) ABS, (b) PC materials.

\section{Experimental results}

Shrinkage of produced parts is measured considering length, width and height of components. The measurement approach is demonstrated in Fig. 4. These three geometrical measurements are of more or less defined whole parts dimensional accuracy. Therefore, these three points are taken to understand the input variables and dimensional accuracy criteria's relation.

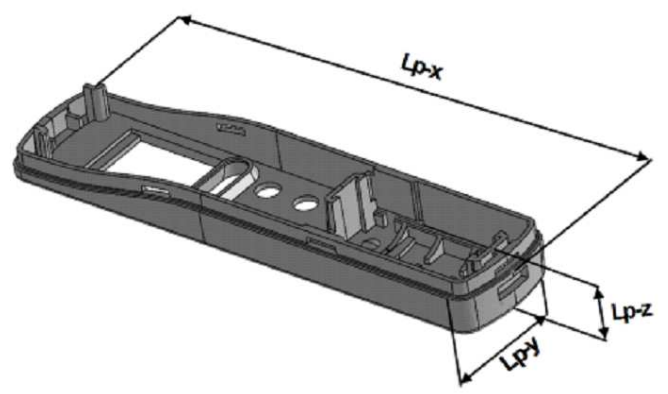

Fig. 4. The length, width and height of the part.

Figure 5 depicts shrinkage percentage changes with changing process temperature at $80 \mathrm{MPa}$ pressure when ABS is used as plastic injection molding material. In this measurement not only one side, but also three different point is considered, are length, width and height for cold and hot runner. Shrinkage increases when process temperature increases in all measurements. Cold runner produces more shrinkage than hot runner. The reason of this result is that cold runner generates more cavities and unfilled area within part and after plastic injection molding is completed, then shrinkage becomes more. But hot runner produces more filled parts and shrinkage is less. Maximum shrinkage is measured at height of parts in hot and cold runner. Therefore, it can be possible to say that height is more sensitive to temperature change than the other dimensions of produced components.

Figure 6 depicts shrinkage percentage changes with changing process temperature at $80 \mathrm{MPa}$ pressure when $\mathrm{PC}$ is used as plastic injection molding material with hot runner and cold runner. Shrinkage increases when process temperature increases in all measurements. As same 


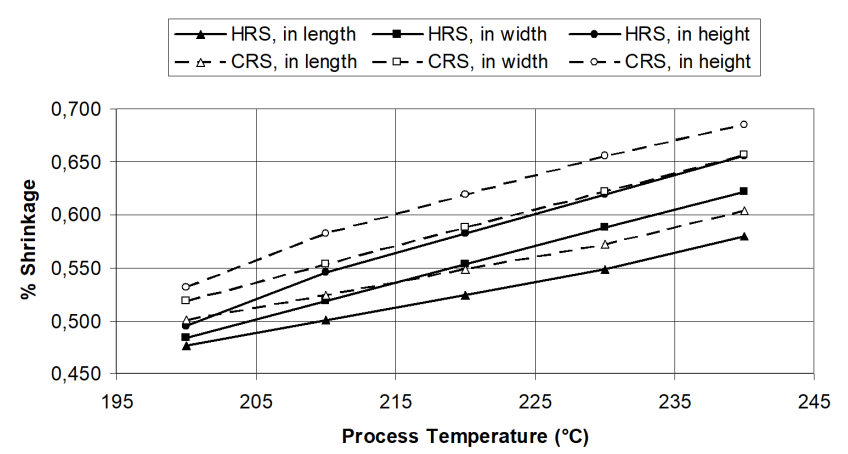

Fig. 5. The length, width shrinkage rates of the part at $80 \mathrm{MPa}$ injection pressure for ABS.

with ABS material, cold runner produces more shrinkage than hot runner for all dimensional measurement. It was clear that similar mechanism occur with ABS material in PC material. Cold runner produces more cavities and unfilled area within part and after plastic injection molding is completed, then shrinkage becomes more. Yet hot runner produces more completed parts during the forming process and shrinkage is less on the all measured dimensions. Maximum shrinkage is measured at height of part and then width in cold runner and same thing occur with hot runner process. Increased percentage of shrinkage with increasing process temperature from $280^{\circ} \mathrm{C}$ to $300^{\circ} \mathrm{C}$ is around fifty percent that is much more than the effect of runner design.

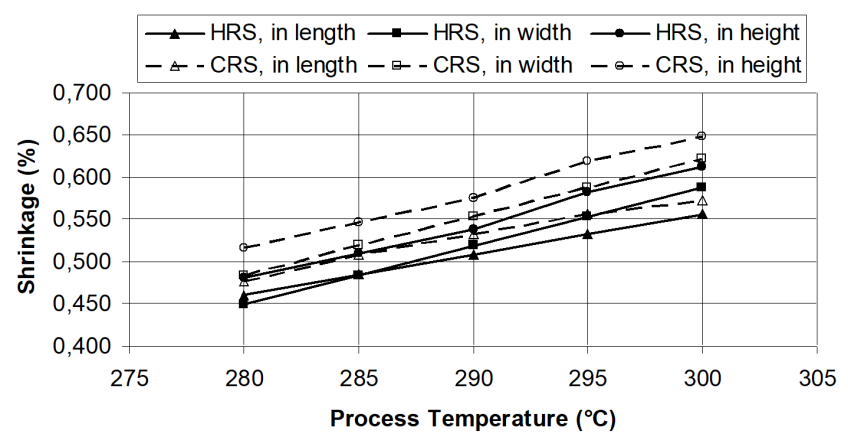

Fig. 6. The length, width, and height shrinkage rates of the part at $80 \mathrm{MPa}$ injection pressure for $\mathrm{PC}$ material.

These results depict that in both plastic material, in other words ABS and PC, molding temperature show the same effects and hot runner produces better quality and accuracy. But more than raw material and various dimension, process temperature is effective to determine the dimensional accuracy of produced plastic parts. In plastic injection molding, in addition to shrinkage, warpage is also measured and needed because just shrinkage is not enough to reach decision that produced parts are of very good considering dimensional accuracy. Figure 7 depicted the measurement methods of warpage for this produced material. By taking this measurement method as reference, the effect of hot runner and cold runner is investigated. Warpage is calculated with $H-h$ values. $H$ represents the height of warped point according to surface plate and $h$ represents the height of the part in the design.

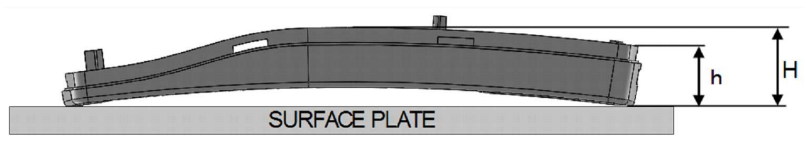

Fig. 7. Demonstration of warpage measurement.

Figure 8 depicts warpage measurement with changing process temperature at constant $80 \mathrm{MPa}$ pressure when ABS material is used as plastic injection molding material with hot runner and cold runner. Warpage increases when process temperature increases in both runner design. Comparing to hot runner, cold runner produces more warpage. Considering the length of warpage, cold runner produces more cavities and unfilled area within part and after plastic injection molding is completed, and these unfilled and nonhomogeneous structure cause warpage in produced plastic injected mold parts. However, hot runner produce more filled parts and more homogeneous structure and warpage is less than cold runner. The raise rate of warpage with increase process temperature is around 40 percent when process temperature increase from 200 to $240{ }^{\circ} \mathrm{C}$.

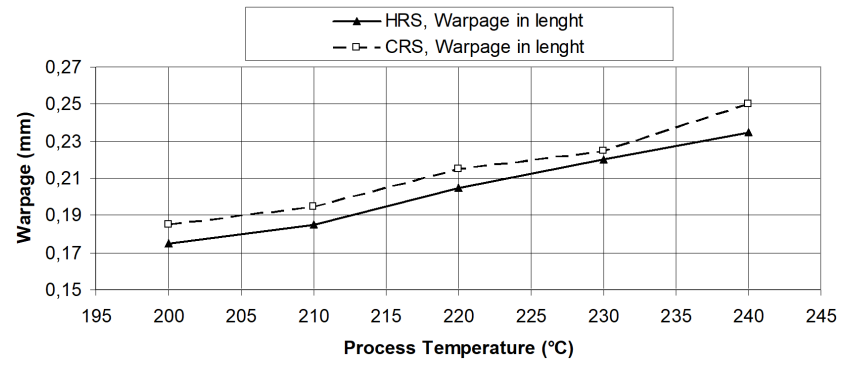

Fig. 8. Warpage percent of ABS made component based on $x$ axis.

Figure 9 depicts warpage measurement with changing process temperature at constant $80 \mathrm{MPa}$ pressure when $\mathrm{PC}$ material is used as plastic injection molding material with hot runner and cold runner. Similar to the ABS material, warpage increases when process temperature increases in hot runner used and cold runner used processes. Cold runner produces more warpage than hot runner. When the length of warpage is taken, cold runner produces more cavities and unfilled area within part and after plastic injection molding is completed, and these unfilled and inhomogeneous structures cause warpage in produced plastic injected mold parts. The mechanism does not change when material is changed from ABS to PC. Therefore, smaller process temperature and hot runner should be used to reduce warpage of components 
made of both ABS and PC material.

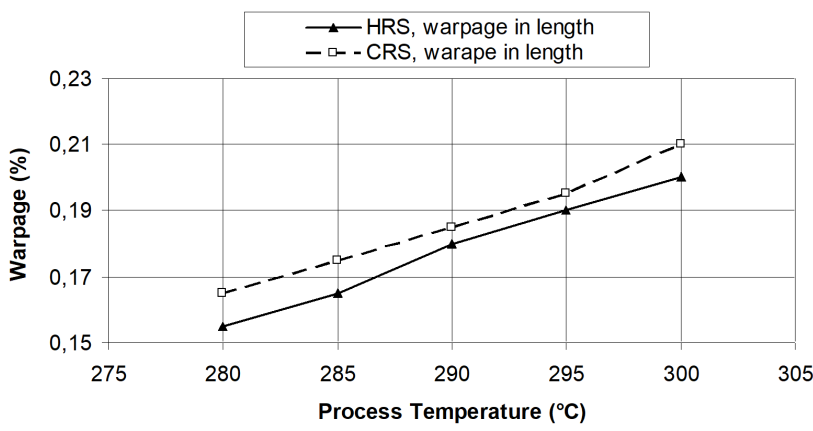

Fig. 9. Warpage percent of PC made component based on $x$ axis.

\section{Numerical validation}

For computer aided engineering software, the mold flow software was used. It was necessary to predict the response of $\mathrm{ABS}$ and $\mathrm{PC}$ material to compare with the experimental data. Figure 10 shows mold flow analysis for predicting volumetric shrinkage for ABS material with hot and cold runner. Besides, Fig. 11 depicts same analysis for PC polymer raw material. There is big difference in between hot runner and cold runner results for shrinkage prediction.

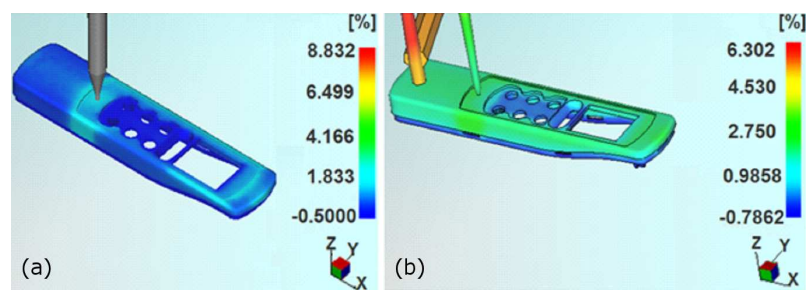

Fig. 10. Mold flow analysis of volumetric shrinkage for ABS material: (a) with hot runner, (b) with cold runner system.

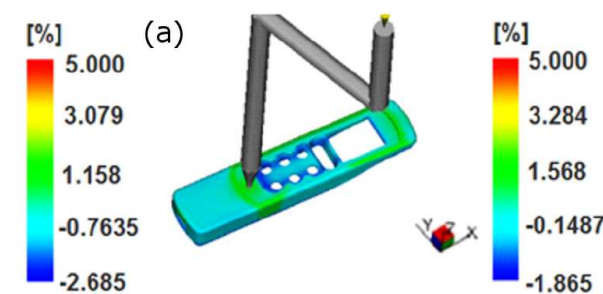

Fig. 11. As in Fig. 10, but for PC material.

The prediction result is depicted in Table II for both cold runner and hot runner design used molding process simulation by using mold flow. When cold runner used, ABS polymer material made component produces around
2.23 percent volumetric shrinkage, but when hot runner used, volumetric shrinkage percentage is around 1.56. Therefore, simulation shows that cold runner produces more shrinkage when it is compared with hot runner. This shows good similarity and validation of experimental data presented above. Table II also shows simulation result of PC polymer raw material. Again cold runner produces 1.38 volumetric shrinkage but hot runner produces 0.95 volumetric shrinkage. Simulation is also validated experimental data for PC material.

TABLE II

Mold flow analysis of average volumetric shrinkage rates for $\mathrm{ABS}$ and $\mathrm{PC}$ at $80 \mathrm{MPa}$

\begin{tabular}{c|c|c}
\hline \hline \multirow{2}{*}{} & \multicolumn{2}{|c}{ Shrinkage rates [\%] } \\
\cline { 2 - 3 } & ABS & PC \\
\hline CRS & 2.23 & 1.38 \\
HRS & 1.56 & 0.95
\end{tabular}

Plastic injection process for these two materials for predicting warpage is also simulated using commercially available mold flow software. Figure 12 depicts the mold flow analysis of $x$ axis warpage of parts made of ABS polymer material, (a) with hot runner, (b) with cold runner system. Figure 13 depicts the predicted warpage for the same condition for PC polymer material. Simulated all conditions show some difference. The obtained prediction is depicted in Table III. When cold runner design is used for simulation of plastic injection molding process for ABS material, average warpage is 0.28 . When hot runner design is used, average warpage is 0.24 . Therefore this prediction shows similar results with experimental data depicted in previous section. Simulation for PC polymer materials also depicts similar response. With hot runner warpage is much less for PC polymer material than when cold runner is used.

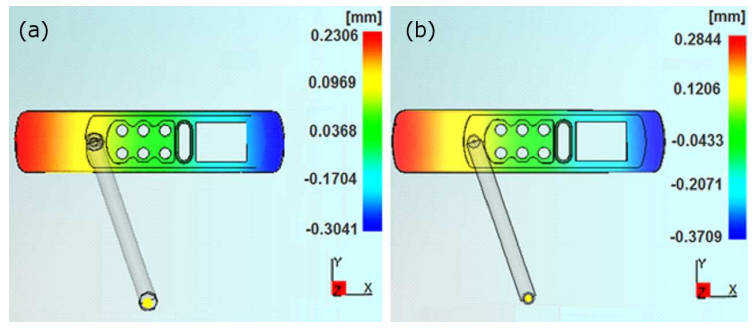

Fig. 12. Mold flow analysis of $x$ axis warpage of parts made of ABS polymer material: (a) with hot runner, (b) with cold runner system.

Simulation depicts that narrowed cross-section on the plastic components causes warpage because it is not filled well. Also the area warpage occurrence is far away from the runner. The area close to runner is more homogeneous and not big warpage is observed. Thus, numerical simulation for both shrinkage and warpage shows similar results with experimentation. Therefore numerical sim- 

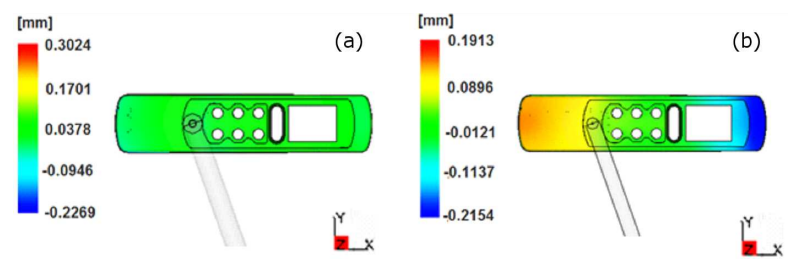

Fig. 13. As in Fig. 12, but for PC polymer material.

TABLE III

Mold flow analysis of predicted $x$ axis warpage occurring after filling process for ABS and PC at $80 \mathrm{MPa}$

\begin{tabular}{c|c|c}
\hline \hline \multirow{2}{*}{} & \multicolumn{2}{|c}{ Average warpage $[\mathrm{mm}]$} \\
\cline { 2 - 3 } & ABS & PC \\
\hline CRS & 0.28 & 0.08 \\
HRS & 0.24 & 0.06
\end{tabular}

ulation can be used to optimize process and so reduce both warpage and shrinkage.

\section{Conclusions}

This study investigated the forming response of two polymer materials, ABS and PC under plastic injection molding process for remote control covers. The input parameters were runner design, in other words hot and cold runner and process temperature. The effect of these parameters on warpage and shrinkage is investigated during producing remote control cover parts. For remote control cover producing, mold is design and fabricated. Experimental study depicts that during forming process of both $\mathrm{ABS}$ and $\mathrm{PC}$ polymer, processing temperature is important. High processing temperature causes big volumetric shrinkage and big warpage. ABS material generates bigger volumetric shrinkage and warpage when it is compared with PC material. Also cold runner causes more volumetric shrinkage and big warpage when it is compared to hot runner. The maximum shrinkage occurs at high dimension of produced part, and the least dimensional error occurs in length of produced part. Mold flow analysis study also shows similar results with experimental data and validates the experimental data. To reduce shrinkage and warpage, hot runner design can be used. Besides, to reduce error, $\mathrm{PC}$ material can be used so that dimensional error can become minimal.

\section{References}

[1] R. Spina, J. Mater. Process. Tech. 155-156, 1497 (2004).

[2] W.C. Bushko, V.K. Stokes, Polym. Eng. Sci. 36, 322 (1996).

[3] K.M.B. Jansen, D.J. Van Dijk, M.H. Husselman, Polym. Eng. Sci. 38, 838 (1998).

[4] A. Demirer, Y. Soydan, A.O. Kapti, Mater. Des. 28, 1467 (2007).

[5] M.C. Huang, C.C. Tai, J. Mater. Process. Tech. 110, 1 (2001)

[6] H. Hassan, N. Regnier, G. Defaye, Int. J. Heat Fluid Flow 30, 1218 (2009).

[7] J.G. Kovacs, B. Siklo, Polym. Test. 30, 543 (2011).

[8] T. Erzurumlu, B.Özçelik, Mater. Des. 27, 853 (2006).

[9] S.J. Liao, D.Y. Chang, H.J. Chen, L.S. Tsou, J.R. Ho, H.T. Yau, W.H. Hsieh, Polym. Eng. Sci. 44, 917 (2004).

[10] J. Pomerleau, B. Sanschagrin, Polym. Eng. Sci. 46, 1275 (2006).

[11] S.J. Liad, W.H. Hsieh, Polym. Eng. Sci. 44, 2029 (2004).

[12] M. Kurt, O.S. Kamber, Y. Kaynak, G. Atakok, O. Girit, Mater. Des. 30, 3217 (2009).

[13] S.J. Liu, Y.C. Wu, W.K. Chen, Plast. Rubber Compos. Process. Appl. 35, 29 (2006).

[14] M.J. Oliveira, A.M. Brito, M.C. Costa, Polym. Eng. Sci. 46, 1394 (2006). 